\title{
Experimental Works and Power Loss Calculations of Surface-Mounted Permanent Magnet Machines
}

\author{
Jang-Young Choi*, Kyoung-Jin Ko, and Seok-Myeong Jang \\ Department of Electrical Engineering, Chungnam National University, Daejeon 305-764, Korea
}

(Received 24 November 2010, Received in final form 28 January 2011, Accepted 28 January 2011)

\begin{abstract}
Surface-mounted permanent magnet (PM) machines were examined experimentally and theoretically, through power loss measurements and calculations. Windage, friction and copper losses were calculated using simple analytical equations and finite element (FE) analyses. Stator core losses were calculated by determining core loss coefficients through curve-fitting and magnetic behavior analysis through non-linear FE calculations. Rotor eddy current losses were calculated using FE analyses that considered the time harmonics of phase current according to load. Core, windage and friction open-circuit losses and copper loss were determined experimentally to test the validity of the analyses.
\end{abstract}

Keywords : power loss calculations, surface-mounted permanent magnet machines, core losses, rotor eddy current losses

\section{Introduction}

Environmental concerns have spurred research into renewable electrical power sources; with wind power one of the most promising [1]. Wind generators are generally divided into two types: gearbox-coupled generators (e.g. induction generators (IGs)), and gearless direct-coupled generators (e.g. permanent magnet synchronous generators (PMSGs)). Compared with IGs, PMSGs have advantages such as reduced overall size and lower installation and maintenance costs [2]. Therefore, they have received increased attention. As wind turbines are totally enclosed, non-ventilated machines located on a tower outdoors in possibly hot environments, it is useful to study their thermal behavior. Assuming that the heat it radiates and that which it absorbs from the sun are approximately balanced, a PMSG's temperature is determined by its power losses. This paper describes experimental and calculated power losses of the PM wind turbine generator shown in Fig. 1. Windage, friction and copper losses were calculated by simple analytical equations. Stator core losses were calculated by determining core loss coefficients through curve-fitting and magnetic behavior analysis through non-linear FE calculations. Rotor eddy current losses

*Corresponding author: Tel: $+82-42-821-7610$

Fax: +82-42-822-4933, e-mail: choi_jy@cnu.ac.kr were calculated using FE analyses that considered time harmonics of phase current according to load. Experimental measurements of core and copper losses were made to test the validity of the calculations.

\section{Power Loss Calculations}

The losses that cause stator heating are copper and iron losses, and those that cause rotor heating are rotor eddy current and mechanical losses (Fig. 2). The calculation of each loss is discussed in the following sections.

\subsection{Copper Loss}

The copper loss, $P_{c u}$, consists of $I^{2} R$ and eddy currents through proximity effects caused by the rotation of the

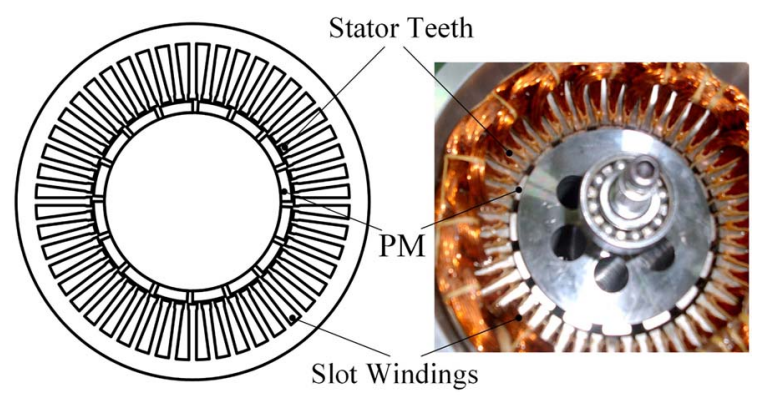

Fig. 1. The PM wind turbine generator with 16-pole rotor and 48-slot stator. 


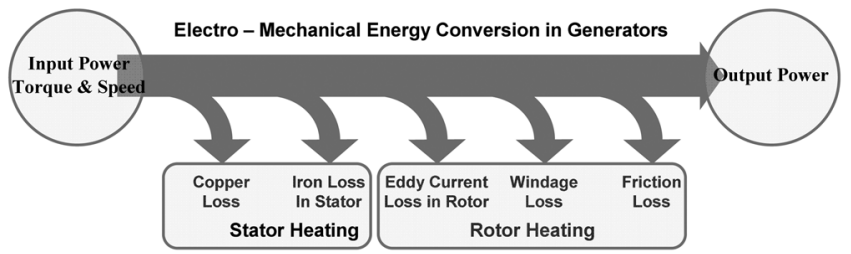

Fig. 2. Power flow diagram of the PM wind turbine generator.

PM. Eddy current loss per volume for round wire can be expressed as:

$$
P_{c u_{-} e d d y}=B_{p}^{2} \omega_{e}^{2} d^{2} / 32 \rho
$$

where $B_{p}$ is the peak flux density in the winding area, $\omega_{e}$ is the electrical angular frequency, and $d$ and $\rho$ are the winding diameter and the resistivity of copper, respectively. However, since rotational speeds of PM wind turbine generators are generally low, eddy current losses in the copper wire can be ignored.

\subsection{Stator Core Loss}

The core loss density in the stator lamination material can be calculated by the Steinmetz equation [3]:

$$
\begin{aligned}
P_{\text {core }} & =P_{h}+P_{e}+P_{a} \\
& =k_{h} f B^{n}+k_{e} f^{2} B^{2}+k_{a} f^{1.5} B^{1.5}
\end{aligned}
$$

where $k_{h}, k_{e}, k_{a}$ and $n$ are the hysteresis, eddy current, anomalous loss coefficients and the Steinmetz constant, respectively. $f$ and $B$ are the operating frequency and the peak flux density in the stator core, respectively. Generally, core loss data provided by steel manufacturers are given for only specific frequencies and are obtained under alternating field. Therefore, to calculate core losses of PM wind turbine generators at various frequencies, the coefficients $k_{h}, k_{e}, k_{a}$ and $n$ in equitation (2) must be derived

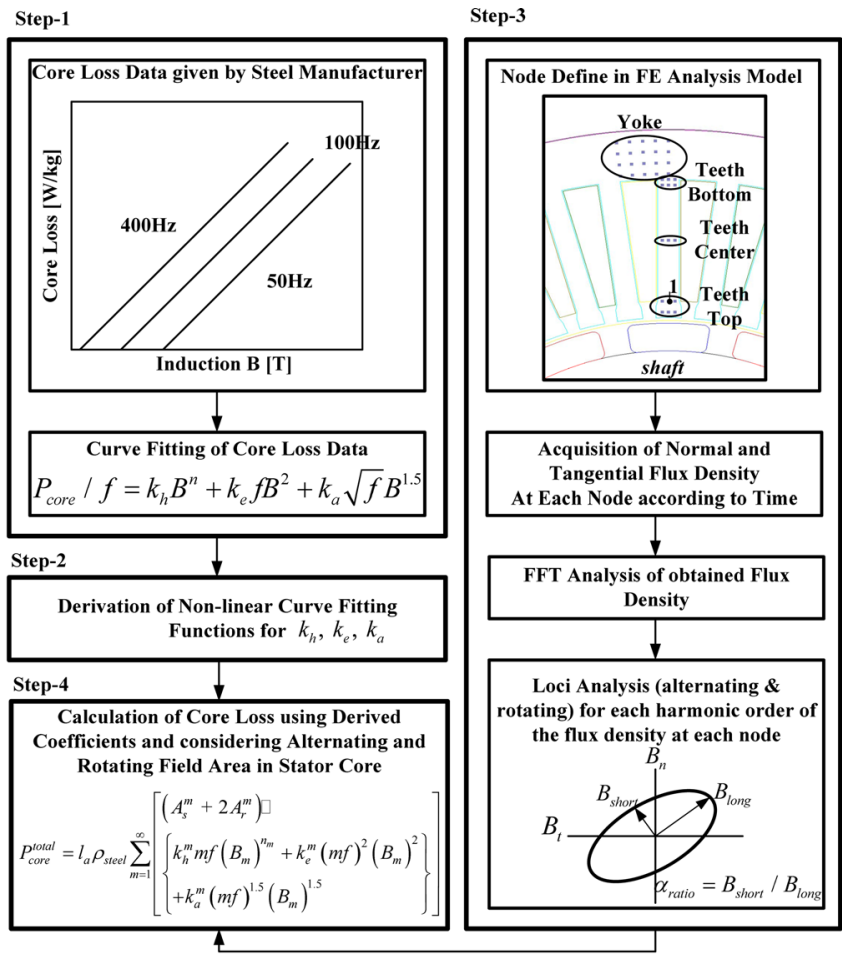

Fig. 3. The calculation procedures of stator core losses.

and the rotating and alternating magnetic fields in the stator core should be separated. The calculations of stator core loss were made as follows (Fig. 3):

Step 1 - the core loss data $\left(P_{\text {core }}\right.$ vs. $\left.B\right)$ provided by the manufacturer were rearranged and plotted as a function of $P_{\text {core }} / f$ vs. $B$ (Fig. 4(a)).

Step 2 - the coefficients in equation (2) were derived by curve fitting $P_{\text {core }} / f$ vs. $B$. The derived coefficients were:

$$
\begin{aligned}
& k_{h}=9 f^{0.4} \times 10^{-4} ; k_{e}=2.2 \cdot f^{-0.68} \times 10^{-3} ; \\
& k_{a}=1.6 \cdot f^{-0.11} \times 10^{-3} ; n=1.11 f^{0.16}-0.009 f+0.93
\end{aligned}
$$

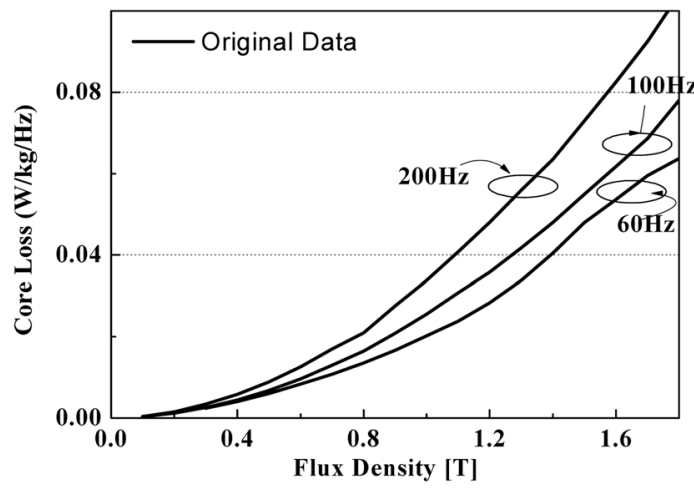

(a)

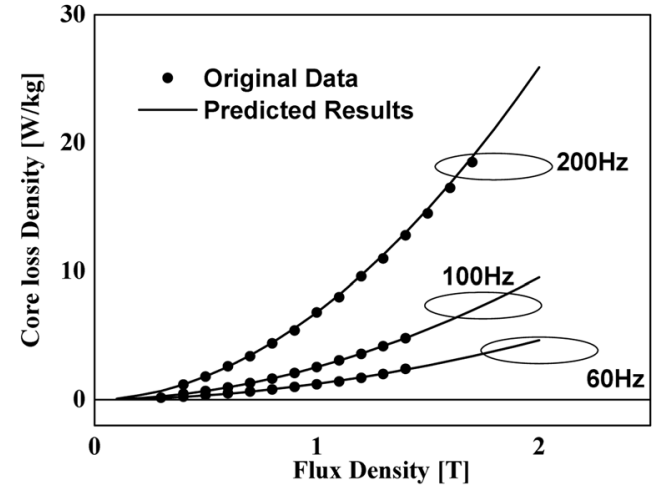

(b)

Fig. 4. (a) $P_{\text {core }} / f$ vs. $B$ curves rearranged from original core loss data and (b) comparison of original data and predicted stator core losses. 


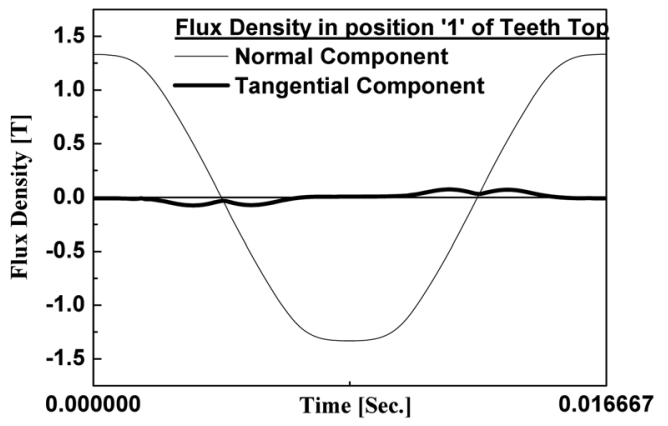

(a)

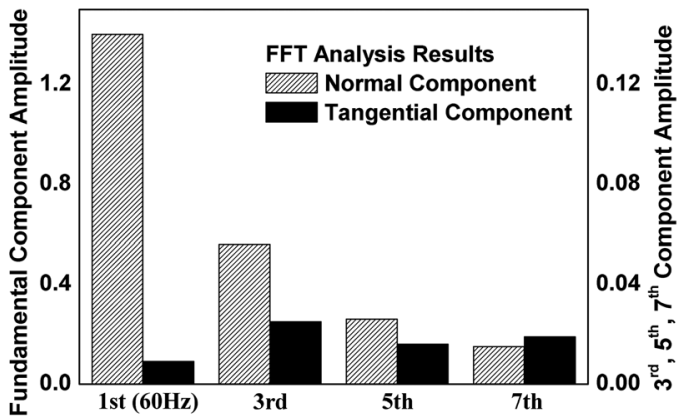

(b)

Fig. 5. Normal and tangential flux densities obtained at node ' 1 ' during 1-cycle: (a) waveforms and (b) FFT analysis results.

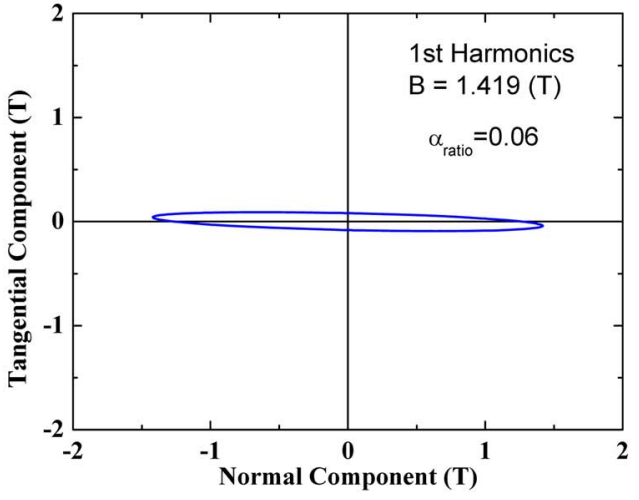

(a)

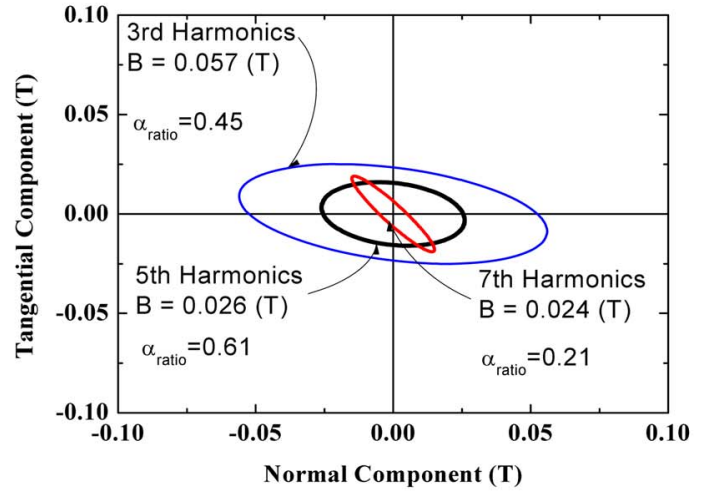

(b)

Fig. 6. Loci for each harmonic order of flux density obtained at node ' 1 ': (a) fundamental component and (b) $3^{\text {rd }}, 5^{\text {th }}$ and $7^{\text {th }}$ harmonic components.

There was good agreement between the original core loss data provided by the steel manufacturer and the results predicted by equation (2) using the core loss coefficients of equation (3) (Fig. 4(b)).

Step 3 - the rotating and alternating magnetic fields in the stator core were separated by analyzing the magnetic field behavior using non-linear FE calculations [4, 5]. The numbers of nodes where flux densities were calculated, in the teeth's tops, centers and bottoms and the stator yoke were 6, 3, 6 and 20, respectively (Fig. 3).

Only the results for node ' 1 ' in the teeth's top region are presented, despite data being obtained for the magnetic field behavior of all the nodes shown in Fig. 3. To analyze magnetic field behavior considering time harmonics, 255 normal and tangential flux density data were obtained under open-circuit conditions, according to the rotor position with time at node ' 1 ' in Fig. 3 (Fig. $5(\mathrm{a})$ ), as FFT analysis requires $2^{\mathrm{n}}-1$ data during the 1cycle. The results of FFT analysis of these waveforms (Fig. 5(b)) show that the main harmonic orders were the $1^{\text {st }}, 3^{\text {rd }}, 5^{\text {th }}$ and $7^{\text {th }}$. Also, loci for each harmonic component of the flux density produced in node ' 1 ' of Fig. 3 were described (Fig. 6). Here the axis ratio [5], $\alpha_{\text {ratio }}=$ $B_{\text {short }} / B_{\text {long }}$, was introduced to separate the alternating and rotating magnetic field regions in the stator core. This ratio (confined between 0 and 1 ) defines the aspect ratio of a particular $B$-locus, with zero corresponding to a pure alternating field and 1 corresponding to a pure rotating field, where the $B$-locus resembles a circle. Although the teeth's top region in the stator core is generally a rotating field region, Fig. 6 shows that the axis ratios of the loci for the fundamental and for the $3^{\text {rd }}, 5^{\text {th }}$ and 7 th harmonic components are closer to 0 and to 1 , respectively. i.e. alternating and rotating fields exist together in same region of the stator core. Therefore, the alternating or rotating field areas in the stator core should be determined by loci according to harmonic order.

Step 4 - Core loss considering the rotating and alternating magnetic fields can be calculated by:

$$
\begin{aligned}
P_{\text {core }}^{\text {total }} & =l_{a} \rho_{\text {steel }} \sum_{k=1}^{N} k \sum_{m=1}^{\infty}\left[( A _ { s } ^ { m } + 2 A _ { r } ^ { m } ) \cdot \left\{k_{h}^{m} m f\left(B_{m}\right)^{n_{m}}\right.\right. \\
& \left.\left.+k_{e}^{m}(m f)^{2}\left(B_{m}\right)^{2}+k_{a}^{m}(m f)^{1.5}\left(B_{m}\right)^{1.5}\right\}\right]
\end{aligned}
$$




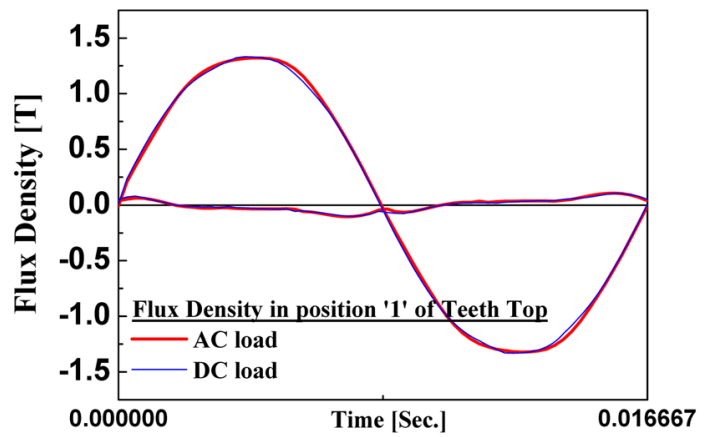

Fig. 7. Normal and tangential flux densities obtained at node ' 1 ' during 1-cycle under ac and de loads.

where $N$ is the $\mathrm{N}^{\text {th }}$ node. $m$ is the $\mathrm{m}^{\text {th }}$ order time harmonic of the normal and tangential flux densities obtained in each region of Fig. 3. The coefficients $k_{h}^{m}, k_{e}^{m}, k_{a}^{m}$ and $n_{m}$ can be obtained from equation (3) by substituting $m f$ for $f$ in each case. $B_{m}$ is the maximum flux density for each time harmonic and is given by $\sqrt{B_{\text {normal }}^{2}+B_{\text {tangential }}^{2}} \cdot A_{s}^{m}$ and $A_{r}^{m}$ respectively represent the alternating and the rotating field areas judged from the loci of the time harmonic for each flux density obtained at the nodes in Fig. 3. $\rho_{\text {steel }}$ is steel's specific gravity. $l_{a}$ is the effective axial length of the PM wind turbine generator. Core loss in the rotating field regions has been experimentally determined to be almost double that in the alternating field regions [6].

Therefore, as shown in equation (4), to calculate core loss accurately, $A_{r}^{m}$ should be multiplied by 2 . The normal and tangential flux densities were also obtained with respect to time at node ' 1 ' in Fig. 3 under ac and dc loads (Fig. 7). Thus, the calculation of core losses considering load conditions can be achieved using the same procedures detailed in step 3 .

\subsection{Rotor Eddy Current Losses}

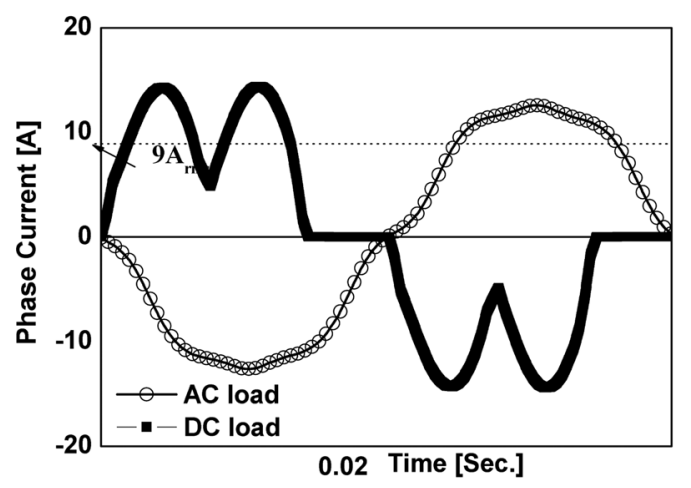

(a)
Slotting effects, the non-sinusoidal stator $\mathrm{mmf}$, and the non-sinusoidal phase current waveform produce time and space harmonics in the air-gap field that induce eddy current losses in the permanent magnets and rotor backiron [7-9]. However, since the rotor's rotation is synchronized with the fundamental stator $\mathrm{mmf}$, permanent magnet (PM) generators generally have relatively small rotor losses, therefore allowing eddy current losses induced in the rotor to be neglected. However, since PM wind turbine generators usually have 3-phase diode rectifiers, the influence on rotor losses of the phase current's time harmonics is very significant.

The phase current waveforms produced by the PM wind turbine generator of Fig. 1 under rated ac and dc loads (Fig. 8(a)) show that, under the rated speed, the effective phase current $(9 \mathrm{~A})$ produced by the PM generator with ac load was almost similar to that with dc load, namely, rectifier load. FFT analysis (Fig. 8(b)) of each of the phase currents shown in Fig. 8(a) shows that the PM generator with rated ac load had $1^{\text {st }}, 5^{\text {th }}$ and $7^{\text {th }}$ order harmonic components of the phase current, with the $1^{\text {st }}$ order harmonic dominating. The PM generator with rated dc load had $1^{\text {st }}, 5^{\text {th }}, 7^{\text {th }}, 11^{\text {th }}$ and $13^{\text {th }}$ order harmonic components of the phase current, with the $1^{\text {st }}$ and $5^{\text {th }}$ dominating. Therefore, the rotor eddy current losses of the PM generator with dc load are likely produced mainly by the $5^{\text {th }}$ order harmonic. The results of the analysis are presented in Chapter III.

\subsection{Other Losses}

Rotational or mechanical losses, $P_{r o t}$, consist of friction, $P_{f r}$, in bearings and windage, $P_{\text {wind }}$. The friction loss in the bearings of small machines can be evaluated as: [10]

$$
P_{f r}=k_{f r} G_{r} \omega_{r} \times 10^{-3}[\Omega]
$$

where $k_{f r}=1-3, G_{r}$ is the mass of the rotor (in $\mathrm{kg}$ ). The windage loss of small machines without a fan at rotational

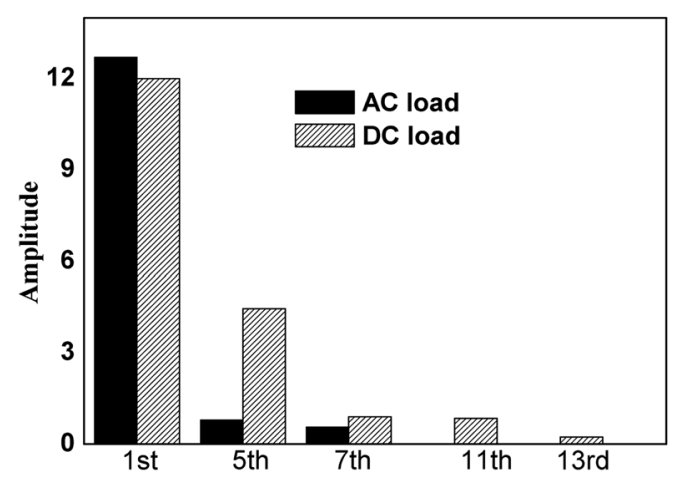

(b)

Fig. 8. (a) Phase current waveforms and (b) FFT analysis of the PM generator with respect to ac and dc load conditions. 


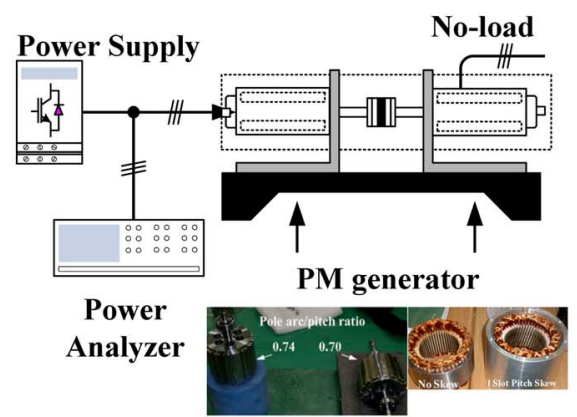

(a)

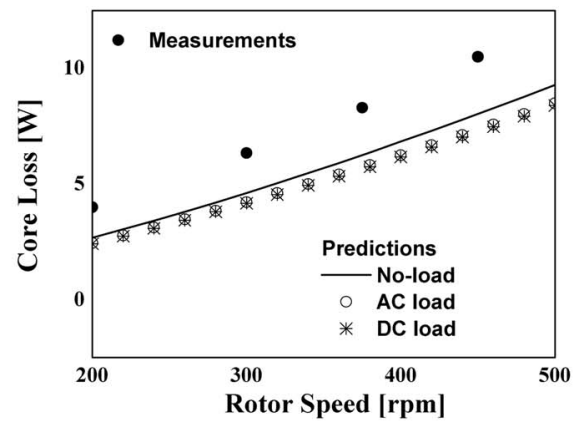

(b)

Fig. 9. Core loss measurements: (a) experimental setup and (b) comparison of predictions with experimental results.

speeds not exceeding $6,000 \mathrm{rpm}$ is: [10]

$$
P_{\text {wind }}=2 D_{r}^{2} l_{a} \omega_{r}^{3} \times 10^{-6}[\mathrm{~W}]
$$

where $D_{r}$ is the outer diameter of the rotor.

\section{Results and Discussion}

\subsection{Stator Core Losses}

Two PM generators were used (Fig. 9(a)) to measure the open-circuit losses, which are the sum of mechanical losses and iron losses under no load. Open circuit losses were obtained by subtracting the power dissipated by one PM generator operated as a motor when it was not coupled to the other PM generator from that when it was coupled. Predicted core losses with respect to rotor speed were compared with measured values (Fig. 9(b)). Core losses without load were higher than those under either load, though whether ac or dc did not greatly affect the results. This indicates that the influence of load conditions on core loss was not significant in this model. When the PM generator was driven at the rated speed of $450 \mathrm{rpm}$, the error between the predicted and measured core losses without load was $c a$. $25 \%$, because the measured values included not only core losses but also rotational losses such as friction and windage.

\subsection{Rotor Eddy Current Losses}

Rotor loss densities were calculated according to harmonic order for current waveforms of the PM generator with ac and dc loads (Fig. 10). Although the amplitude of the $1^{\text {st }}$ order harmonic was $c a .20 \times$ that of the $5^{\text {th }}$ order harmonic (Fig. 8(b)), the PM generator with ac load had a rotor loss density due to the $5^{\text {th }}$ order harmonic $c a .4 .5 \times$ that due to the $1^{\text {st }}$ order harmonic. Under dc loads, the amplitude of the $1^{\text {st }}$ order harmonic was $c a .2 .5 \times$ that of the $5^{\text {th }}$ order harmonic (Fig. 8(b)), while the rotor loss density due to the $5^{\text {th }}$ order harmonic was $c a .120 \times$ that due to the $1^{\text {st }}$

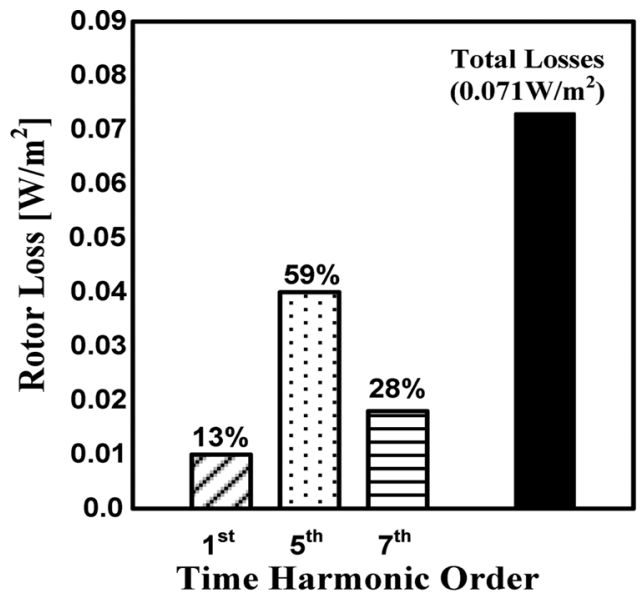

(a)

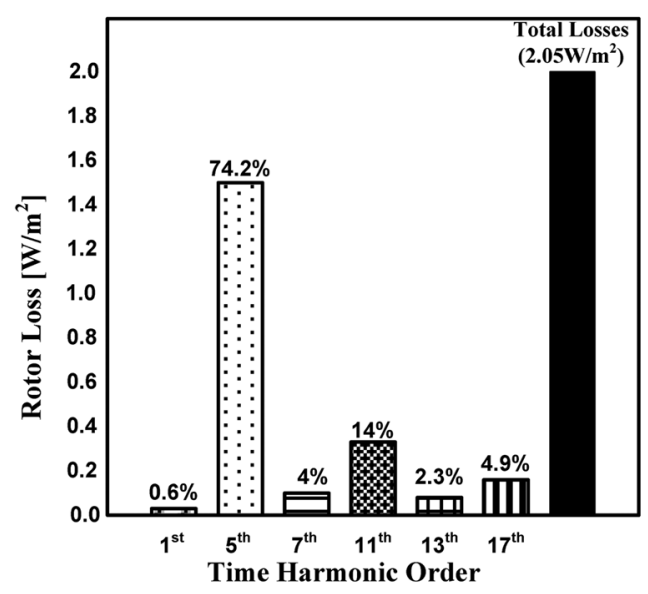

(b)

Fig. 10. FE calculations of rotor eddy current loss: with (a) ac and (b) dc loads.

order harmonic (Fig. 10(b)). Although the effective phase currents of the PM generator were similar with ac and dc loads, the rotor loss density with dc loads was ca. $30 \times$ larger than that with ac loads, because the amplitude of the phase current's $5^{\text {th }}$ harmonic component under $\mathrm{dc}$ 


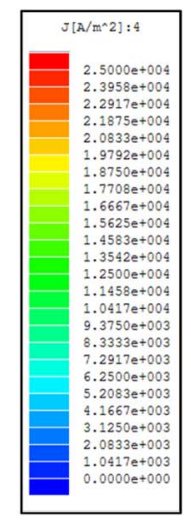

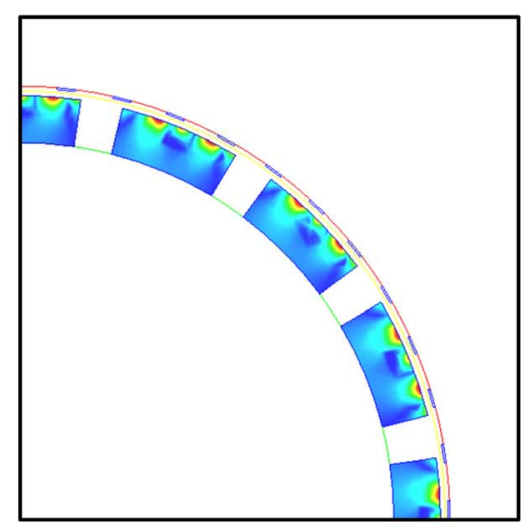

(a)

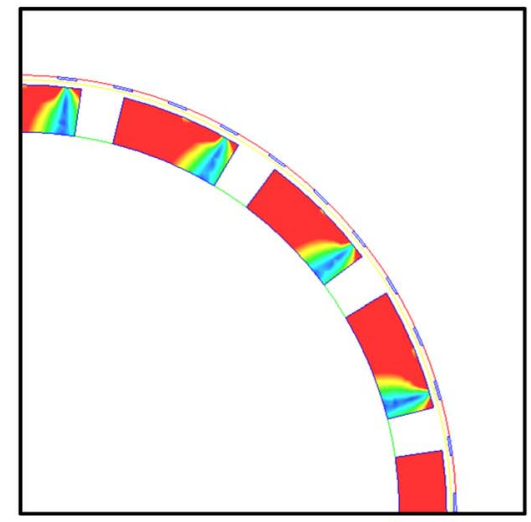

(b)

Fig. 11. Eddy current distribution under (a) ac and (b) dc loads.
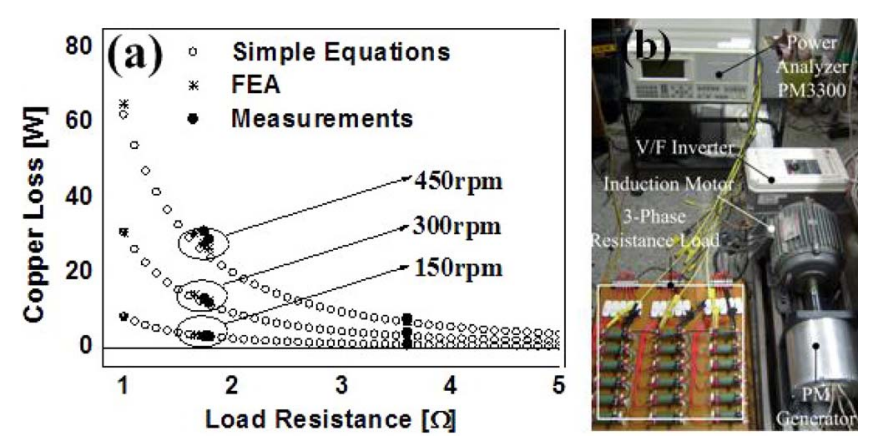

Fig. 12. Copper losses: (a) comparison of predictions with measurements and (b) apparatus for measuring phase current according to load resistance at various rotor speeds.

loads was much larger than that of the PM generator with ac loads. Therefore, despite low rotational speed, eddy current losses should be predicted when the PM generator has a rectifier circuit. As expected from Fig. 10, the eddy current distribution under dc loads is more prominent than under ac loads (Fig. 11).

\subsection{Copper Losses}

A power analyzer, resistive load bank, motor with an inverter as a mechanical input, and test machine (Figure 12(b)) were used to measure copper losses. The values obtained agreed well with predicted values over a range of load resistances and various rotor speeds (Fig. 12(a)).

\subsection{Total Losses}

Table 1 lists the losses in the PM generator shown in Fig. 1 at a rated speed of $450 \mathrm{rpm}$ and rated load of $400 \mathrm{~W}$. The losses can be used to predict the efficiency and thermal behavior of the PM generator. In addition, losses can be calculated at various speeds and loads. The calculated results agreed well with measured data.
Table 1. Estimated Losses: Rated Load, 400 W, Rated Speed, $450 \mathrm{rpm}$

\begin{tabular}{lccc}
\hline \hline Loss & $\begin{array}{c}\text { Simple } \\
\text { Equations }\end{array}$ & FEM & $\begin{array}{c}\text { Measure- } \\
\text { ments }\end{array}$ \\
\cline { 1 - 3 } Copper Loss & $28 \mathrm{~W}$ & $27 \mathrm{~W}$ & \multirow{2}{*}{$30 \mathrm{~W}$} \\
\hline Core Loss (no-/ac-/dc- load) & $7.8 \mathrm{~W} / 7.1 \mathrm{~W} / 7.0 \mathrm{~W}$ & \\
\cline { 1 - 3 } Windage Loss & $0.1 \mathrm{~W}$ & - & \multirow{2}{*}{$10.5 \mathrm{~W}$} \\
\cline { 1 - 3 } Bearing Friction Loss & $1.4 \mathrm{~W}$ & - & \\
\cline { 1 - 3 } Rotor Loss & & $2.05 \mathrm{~W} / \mathrm{m}^{2}$ & - \\
\hline
\end{tabular}

\section{Conclusion}

Experimental and calculated power losses of a surfacemounted PM machines were investigated. Simple analytical expressions of windage, friction and copper losses were established. Stator core losses were calculated by curve fitting of original core loss data and separating alternating and rotating magnetic fields through FFT analysis of time-varying magnetic fields in the stator core. Calculation of eddy current losses according to load was undertaken by investigating time harmonics of in phase current under ac and dc loads. Measured open-circuit and copper loss measurements confirmed the validity of the calculations.

\section{Acknowledgment}

This work has been supported by KESRI (20101020300540 and 20101020300520), which is funded by MKE (Ministry of Knowledge Economy).

\section{References}

[1] A. J. G. Westlake, J. R. Bumpy, and E. Spooner, IEE 
Proc.-Electr. Power Appl. 143, 269 (1996).

[2] W. Wu, V. S. Ramsden, T. Crawford, and G. Hill, Conf. Rec. IEEE Industry Application Conference 1, 147 (2000).

[3] Y. Chen, and P. Pillay, 37th IAS Annual Meeting Conference Record 2, 759 (2002).

[4] L. Ma, M.Sanada, S. Morimoto, and Y. Takeda, IEE Proc.-Electr. Power Appl. 150, 747 (2003).

[5] M. Enokizono, T. Suzuki, J. Sievert, and J. Xu, IEEE Trans. Magn. 26, 2562 (1990).

[6] D. R. Son, Final Report for Technology Development of
Core Loss Analysis and Measurements, National Project, Department of Trade Industry, Korea (1997).

[7] K. Atallah, D. Howe, P. H. Mellor, and D. A. Stone, IEEE Trans. Ind. Appl. 36, 1612 (2000).

[8] N. Boules, Electric Machines and Electromechanics 6, 527 (1981).

[9] P. J. Hor, Z. Q. Zhu, and D. Howe, IEEE Trans. Magn. 35, 3601 (1999).

[10] Jacek F. Gieras and Mitchell Wing, Permanent Magnet Motor Technology, Marcel Dekker Inc. New York, NY (2002). 